\title{
Climate change: linking adaptation and mitigation through agroforestry
}

\author{
Louis V. Verchot · Meine Van Noordwijk • Serigne Kandji · Tom Tomich • \\ Chin Ong · Alain Albrecht · Jens Mackensen · Cynthia Bantilan • \\ K. V. Anupama $\cdot$ Cheryl Palm
}

Received: 25 August 2004/ Accepted: 23 May 2006

(C) Springer Science+Business Media B.V. 2007

\begin{abstract}
Agriculture is the human enterprise that is most vulnerable to climate change. Tropical agriculture, particularly subsistence agriculture is particularly vulnerable, as smallholder farmers do not have adequate resources to adapt to climate change. While agroforestry may play a significant role in mitigating the atmospheric accumulation of greenhouse gases (GHG), it also has a role to play in helping smallholder farmers adapt to climate change. In this paper, we examine data on the mitigation potential of agroforestry in the humid and sub-humid tropics. We then present the scientific evidence that leads to the expectation that agroforestry also has an important role in climate change adaptation, particularly for small holder farmers. We conclude with priority research questions that need to be answered concerning the role of agroforestry in both mitigation and adaptation to climate change.
\end{abstract}

Keywords Tropical agriculture - Small-scale farmers · Rural development · Poverty alleviation

L. V. Verchot $(\bowtie) \cdot$ M. Van Noordwijk $\cdot$ S. Kandji $\cdot$ T. Tomich $\cdot$ C. Ong International, Centre For Research In Agroforestry (ICRAF), United Nations Avenue, P.O. Box 30677, Nairobi, Kenya e-mail: L.verchot@cgiar.org

\section{A. Albrecht}

Institut de Recherche pour le Développement (IRD) and International Centre for Research in Agroforestry (ICRAF), United Nations Avenue, P.O. Box 30677, Nairobi, Kenya

\section{J. Mackensen}

United Nations Environment Programme (UNEP), United Nations Avenue, P.O. Box 30552, Nairobi, Kenya

C. Bantilan · K. V. Anupama

International Crops Research Institute for the Semi-Arid Tropics (ICRISAT), Patancheru 502324

Andhra Pradesh, India

C. Palm

The Earth Institute at Columbia University, MC 4335, 535 West 116th Street, New York, NY 10027, USA 


\section{Introduction}

Developing countries are going to bear the brunt of climate change and suffer most from its negative impacts. Global conventions are not sufficiently effective to halt the increase of atmospheric greenhouse gases (GHG) concentrations, and we now accept that the primary drivers of climate change are not going to stop. Mitigation efforts will therefore only provide a partial softening of the effects of climate change. Local climates and terrestrial ecosystems will change, threatening biota and human livelihoods. Yet, even as climate changes, food and fiber production, environmental services and rural livelihoods must improve, and not just be maintained. The status quo in the developing world is not acceptable. Developing countries are faced with urgent needs for development, to improve food security, reduce poverty and provide an adequate standard of living for growing populations.

Large percentages of the populations of developing countries depend upon agriculture for their livelihoods. Climate change is already affecting agriculture in these countries negatively and this situation is likely to worsen. Much effort will be needed to integrate what is known about likely climate change into national development planning (Abeygunawardena et al. 2003). Mitigation measures in the agriculture and forestry sectors are generating much interest as a potential source for additional income to otherwise weak rural areas and as a means of fueling adaptation to climate change. Within the United Nations Framework Convention on Climate Change (UN FCCC) negotiation process, the development of mitigation and adaptation activities has been dealt with as separate matters, and adaptation was largely ignored in favor of mitigation. It is only recently that adaptation measures were given more importance in the UNFCCC negotiations (see UNFCCC COP8 and the Delhi Declaration).

The discussion of the potential synergies between adaptation and mitigation measures is only just starting and the debate is all too often reduced to a discussion of the costs of global adaptation versus global mitigation. Recent debates within the UNFCCC process on the relation between global adaptation and mitigation measures lack substance due to lack of pertinent experience on the ground. Discussions are often treated in a very generalized manner and are not specifically related to distinct sectors such as agriculture or forestry. A practical understanding of the link between adaptation and mitigation measures does not yet exist. However, for some decades now agricultural research has been focusing on the questions of increasing the resilience (against drought, erosion, fertility loss, etc.) and productivity of agricultural systems. Increasing system resilience is directly related to increasing the adaptive capacity of farmers.

Agroforestry provides a particular example of a set of innovative practices that are designed to enhance productivity in a way that often contributes to climate change mitigation through enhanced carbon sequestration, and that can also strengthen the system's ability to cope with adverse impacts of changing climate conditions. This paper looks into the adaptation and mitigation functions of agroforestry systems, reexamines the concept of sustainability and explores how agroforestry systems (and other innovations for that matter) might enhance resilience and thereby reduce vulnerability of smallholder farmers in the tropics.

\section{The expected impacts of climate change on agricultural production}

While there have been gains in recent years, more than 800 million people in the world are still chronically malnourished, and 1,100 million live in absolute poverty (FAO 1999). 
Large percentages of the populations in developing countries derive their livelihoods from agriculture and are therefore particularly vulnerable to climate change. Populations of developing countries, particularly in South Asia and sub-Saharan Africa continue to grow at high rates, while the extent of harvested areas has stagnated or is decreasing in many grain producing areas of the world (Mann 1997). To feed everyone adequately, world food production will have to double within the next 30 years (Cleaver and Schreiber 1994). But, the shortfall in domestic cereals production in the developing world is expected to widen from around than 100 million tons in 1997 to around 190 million tons in the year 2020 (Rosegrant et al. 2001). In many regions of the world, there will be a limited ability for new varieties and increased fertilizer use to further increase yields (Huang et al. 2002). On top of this, degradation of soil and water resources has reached alarming proportions (Vasil 1998; Smaling et al. 1997) and will undermine future efforts to boost agricultural productivity.

Climate change will add additional stress to an already overtaxed system. The risk of losing the gains of the Green Revolution, which has largely eliminated the famines of the 1950s and 1960s is real. For example, projections suggest that the South Asia summer monsoon will be delayed and become less certain, and that temperature increases will be most intense during the winter season (Lal et al. 2001). Several modeling studies that combine spatial analysis with an analysis of the physiological effects of changes in $\mathrm{CO}_{2}$, rainfall and temperature have been done in South Asia to assess the impact of climate change on crop production (Aggarwal and Sinha 1993; Rao and Sinha 1994; Kropff et al. 1996; Berge et al. 1997; Saseendran et al. 2000; Aggarwal and Mall 2002). These studies have shown a decrease in the growing season and yield of most crops as temperature increases. Such reductions were only partially offset by a positive response to increased $\mathrm{CO}_{2}$ concentrations.

Farmers in the developing world already have a number of sustainability challenges, and climate change will affect a number of these (Table 1). For example, climate change will affect pest and disease incidence and virulence in ways that are poorly understood at present. Diseases and insect populations are strongly dependent upon temperature and humidity, and changes could alter their distributions and virulence. For example, at $16^{\circ} \mathrm{C}$ the length of the latent period for yellow rust is small, but increases as temperature exceeds

Table 1 Examples of stress factors affecting smallholder farmers in the tropics with indications of the impact of climate change on the stress factors

\begin{tabular}{lc}
\hline Stress factor & $\begin{array}{c}\text { Climate } \\
\text { signal }\end{array}$ \\
\hline Land access & No \\
Markets (inputs, outputs; access, prices) & Yes \\
Knowledge (basic principles, innovative cap.) & No \\
Technologies (strategic \& tactical interventions) & No \\
Water (drought, flooding, irrigation, drainage) & Yes \\
Soil fertility & Yes \\
Pest \& disease & Yes \\
On-farm labor (household size, off-farm activities, & No \\
$\quad$ illness) & \\
Weeds & Yes \\
Potential production of germplasm used & Yes \\
Dissatisfied customers & No \\
\hline
\end{tabular}


$18^{\circ} \mathrm{C}$ (Nagarajan and Joshi 1978). The appearance of black rust in north India in the 1960s and 1970s was related to the temperature dependent movement of spores from south to north India (Nagarajan and Joshi 1978).

Climate change will have a direct effect not only on rainfed crops, but also on water storage, putting increased stress on water availability for irrigation. Since availability of water will be limited, agriculture will compete for other uses of water, further stressing farming systems. There will also be impacts on soil resources. Changes in precipitation patterns and amount, and changes in temperature will influence crop growth through changes in soil water content, runoff and erosion, workability, nutrient cycles, salinization, biodiversity, and soil organic matter. Sea level rise will be problematic for low lying areas and may lead to salt-water ingression rendering large areas of land unsuitable for conventional agriculture.

Climate change will also severely set back agricultural development in Africa. An analysis of maize production in the tropics by Jones and Thornton (2003) suggests that maize production in the tropics will decline by $10 \%$ on average, but this figures masks large variations. There will be winners and losers as climates change. For example, the Sahel and Southern Africa regions are likely to suffer disproportionately, while the East Africa highlands are likely to enjoy increased productivity.

Climate induced changes must be considered in light of other stress factors in today's world including economic globalization, urbanization and its effect on rural labor and land availability, population growth and its effect on water and other resource availability, crop pests and diseases, land degradation and low soil fertility, poverty, diseases such as AIDS and malaria, etc. In some instances, the impact of additional stresses to agriculture and rural livelihoods from climate change may be small in comparison to these other stressors. Additionally, the gains of adapting agriculture to climate change may not be realized if they are negated by other factors. For example, liberalized trading policies under the compulsion of international agreements may expose the newly adapted crops/agricultural products to open competition with products from areas that are not suffering from climate change stress. Examples of these types of problems are already available. For example, gains facilitated by agricultural research and development and other support systems for oilseed crops in dry areas and apple and flower crops in hill areas in India, were nullified once government trade policies allowed liberal imports of these products under open general license. The new adaptation options will have to be compatible with emerging economic changes associated with globalization. This puts still greater pressure on agricultural research and development efforts devoted to identify and evolve adaptation options against climate change. New developments will have to satisfy multiple goals.

The climate change issue has presented decision makers with a set of formidable complications. There are a considerable number of uncertainties (which are inherent in the complexity of problem), such as: the potential for irreversible damage to ecosystems, a very long planning horizon, long time lags between GHG emissions and effects, wide regional variation in causes and effects, the global scope of the problem and the need to consider multiple GHG and aerosols. Yet, an ostrich strategy of waiting until all uncertainties regarding climate change have been eliminated would be very short-sighted, given the irreversibility of current change and the response time of the ocean-atmosphere system in global change processes. The value of better information about climate change processes, impacts, and the response to arrest these risks is likely to be great. By identifying the resources on which adaptation can be based we may contribute to the maintenance and strengthening of these resources, and recognize where vulnerability will be highest. 


\section{Contribution of agriculture to climate change mitigation}

A number of improved farming practices can increase the sustainability of farming systems and contribute to reducing farmers' vulnerability to climate variability while sequestering carbon from the atmosphere (Table 2). Generally, we have a good idea how these practices affect $\mathrm{C}$ stocks in the agroecosystem (IPCC 2001). We have a much poorer understanding of the effects of these improved practices on non-carbon dioxide $\left(\mathrm{CO}_{2}\right)$ GHG. Some generalizations can help us anticipate the effects of different practices. For example, improving soil $\mathrm{N}$ nutrition through fertilization of crops and pastures increases $\mathrm{N}_{2} \mathrm{O}$ (nitrogen compounds) emissions from soils and sometimes decreases the soil $\mathrm{CH}_{4}$ sink (Steudler et al. 1989; Keller et al. 1990; Hansen et al. 1993; Hutsch et al. 1993, 1994; Hutsch 1996; Mosier and Delgado 1997). In fertilized systems, $\mathrm{N}_{2} \mathrm{O}$ losses are generally on the order of $0.2-2.5 \%$ of the applied N (e.g., Crill et al. 2000; Weitz et al. 2001). High input of $\mathrm{N}$ and soil compaction can result in the reduction of sink strength of soils for $\mathrm{CH}_{4}$ and even conversion of soils from a sink for atmospheric $\mathrm{CH}_{4}$ (methane) into a source (Hansen et al. 1993; Dunfield et al. 1995; Palm et al. 2002). In systems where legumes are managed to contribute to $\mathrm{N}$ nutrition, there is little information on the amounts of $\mathrm{N}_{2} \mathrm{O}$ produced or the effect on $\mathrm{CH}_{4}$ consumption. Improved organic matter and flooding management in irrigated rice can decrease $\mathrm{CH}_{4}$ emission from paddies (Wassman et al. 2000; Jain et al. 2000).

Agroforestry has a particular role to play in mitigation of atmospheric accumulation of GHGs (IPCC 2000). Of all the land uses analyzed in the Land-Use, Land-Use Change and Forestry report of the IPCC, agroforestry offered the highest potential for carbon sequestration in non-Annex I countries (Fig. 1). Agroforestry has such a high potential, not because it is the land use practice with the highest carbon density, but because there is such a large area that is susceptible for the land use change $(630 \times 106 \mathrm{ha})$. Improved agroforestry systems that reduce the vulnerability of small-scale farmers and that help them

Table 2 Examples of promising improved agricultural practices and their impact on non- $\mathrm{CO}_{2}$ GHG emissions. All of these options increase $\mathrm{C}$ stocks in the agricultural landscape (Adapted from IPCC 2000)

\begin{tabular}{ll}
\hline Action & Non- $\mathrm{CO}_{2}$ \\
& $\mathrm{GHG}$ \\
\hline Remove marginal land from production & $?$ \\
Restore degraded land & $+\mathrm{N}_{2} \mathrm{O}$ \\
Reduced tillage & $?$ \\
Decrease biomass burning & $\pm \mathrm{N}_{2} \mathrm{O}$ \\
Introduce trees into agricultural landscapes & $?$ \\
Better rice management (cultivars, water & $+\mathrm{N}_{2} \mathrm{O}-\mathrm{CH}_{4}$ \\
$\quad$ management) & \\
Agroforestry (better management of trees on & $?$ \\
$\quad$ croplands) & \\
Elimination of bare fallow & $\pm \mathrm{N}_{2} \mathrm{O}$ \\
Irrigation water Management & $\pm \mathrm{N}_{2} \mathrm{O}$ \\
Introduce forages into rotations & $?$ \\
Increased grassland productivity & $+\mathrm{N}_{2} \mathrm{O}$ \\
Erosion control & $?$ \\
Increase soil P and K & $?$ \\
Decrease shifting cultivation & + \\
Animal waste recycling & $\pm \mathrm{N}_{2} \mathrm{O}$ \\
Legumes instead of N fertilizer & $?$ \\
\hline
\end{tabular}




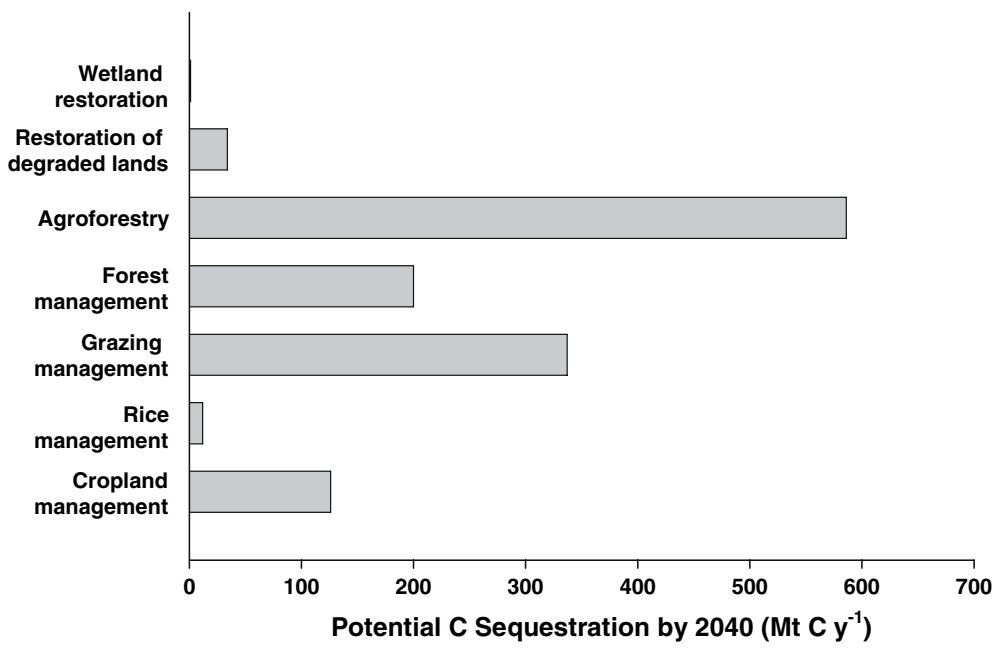

Fig. 1 Carbon sequestration potential of different land use and management options (adapted from IPCC 2000)

adapt to changing conditions often meet the conditions for an eligible afforestation/ reforestation (A/R) activity in the Clean Development Mechanism (CDM). These systems can be promoted through CDM projects to create synergies between mitigation and adaptation and to meet the requirements that CDM projects produce social as well as environmental benefits.

Work through the Alternatives to Slash and Burn Program (ASB) has documented (Palm et al. 2004) the carbon sequestration potential of agroforestry systems on the margins of humid tropical forests (Fig. 2). The carbon sequestration values for these agroforestry systems are reported as time-averaged carbon, reflecting the fact that they are rotational systems with repeated harvest and regrowth. Agroforestry systems in these agroecozones generally tend to be tree-based production systems such as the jungle rubber system of Sumatra, mixed cocoa and fruit tree plantations of Cameroon, peach palm systems of Peru, or the pine-banana - coffee system of eastern Java. The results of this

Fig. 2 Summary of $\mathrm{C}$ stocks at maturity in different ecosystems of the humid tropics. Data are from the benchmark sites of the Alternatives to Slash and Burn Programme of the Consultative Group for International Agricultural Research (CGIAR)

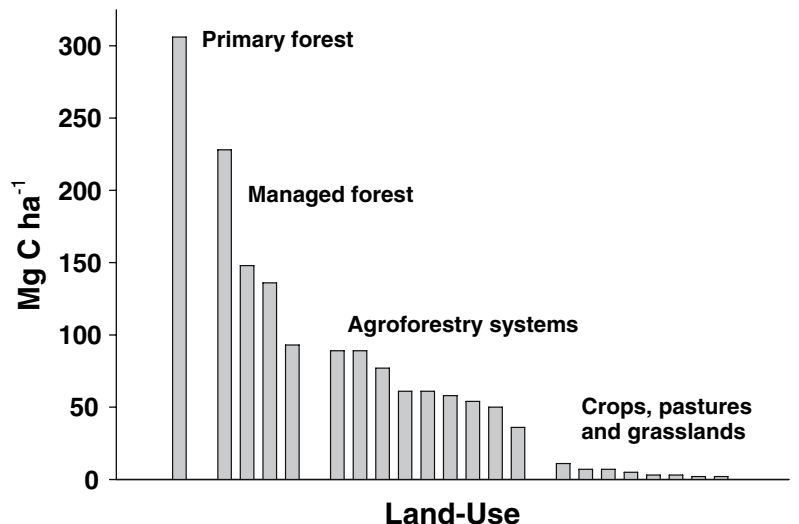


analysis showed that conversion of primary tropical forests to agriculture or grassland results in the loss of about $370 \mathrm{Mg} \mathrm{C} \mathrm{ha}^{-1}$. Managed or logged forests have about half the $\mathrm{C}$ stocks of primary forests. Agroforestry systems contain $50-75 \mathrm{Mg} \mathrm{C}^{-1}$ compared to row crops that contain $<10 \mathrm{Mg} \mathrm{C}^{-1}$. Thus converting row crops or pastures to agroforestry systems can greatly enhance the $\mathrm{C}$ stored in aboveground biomass.

Agroforestry also compares well with other land-uses with respect to other GHG. In Sumatra, a jungle rubber system had lower $\mathrm{N}_{2} \mathrm{O}$ emissions than a primary forest, but also lower $\mathrm{CH}_{4}$ uptake (Tsuruta et al. 2000). However, agroforestry systems that include nitrogen-fixing species may not compare as well. For example, in Sumatra, multi-story coffee with a leguminous tree shade canopy had $\mathrm{N}_{2} \mathrm{O}$ emissions five times higher than open-grown coffee and about half the $\mathrm{CH}_{4}$ uptake (Fig. 3. Verchot et al. unpublished data). In Peru, agroforestry systems (multistrata coffee and a peach palm plantation) wit leguminous cover crops had lower $\mathrm{N}_{2} \mathrm{O}$ emissions than both intensive and low-input agriculture, and similar emissions to a nearby secondary forest (Palm et al. 2002). Soil uptake of $\mathrm{CH}_{4}$ was similar to other land-use systems, with the exception of the intensive agriculture site, which became a net source to the atmosphere.

Also under the ASB program, Gockowski et al. (2001) conducted a tradeoff analysis between carbon storage and profitability of different forestry and agroforestry systems in Cameroon and concluded that tropical deforestation is profitable and can sometimes lead to poverty reduction. Typically, there are tradeoffs between carbon stored and profit, and while there are no win-win (high carbon and high profit) land uses, there are certainly some no regrets options with medium to high profit and medium carbon stocks. Policy

Fig. $3 \mathrm{~N}_{2} \mathrm{O}$ emission and $\mathrm{CH}_{4}$ uptake by soils under different land uses in Sumatra. Note the shade coffee uses nitrogen fixing trees as a shade source, which results in increased $\mathrm{N}_{2} \mathrm{O}$ emissions and slightly suppressed $\mathrm{CH}_{4}$ uptake. (Source: Verchot et al. unpublished data)
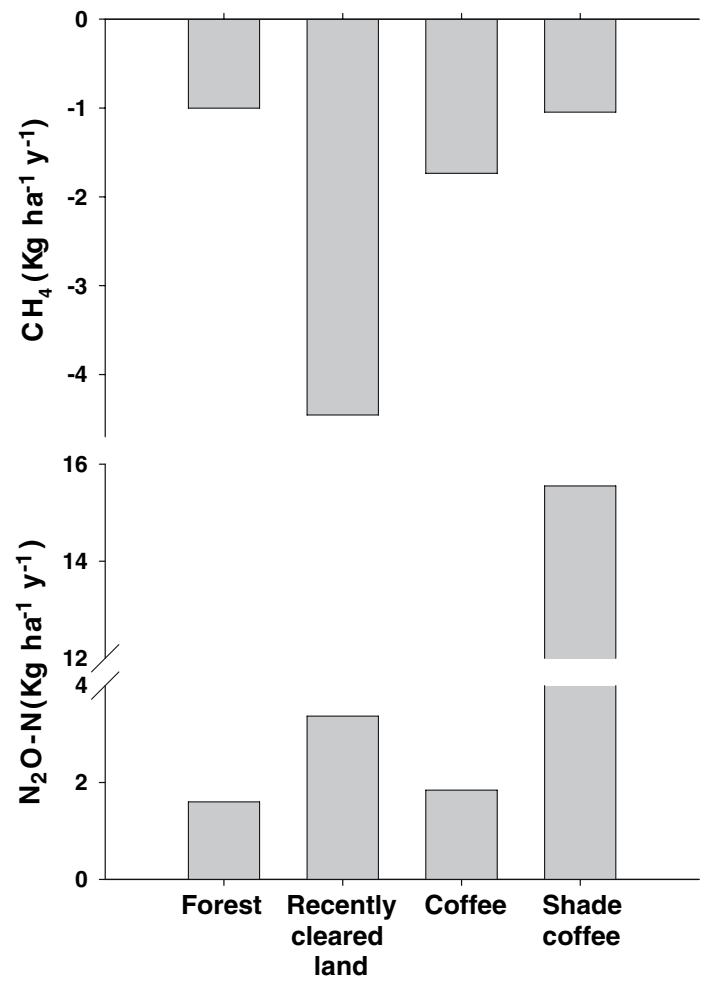
makers and project developers could promote these options as part of a climate change mitigation scheme (Fig. 4).

Agroforestry also has an important carbon sequestration role to play in the sub-humid tropics, and may contribute to reducing farmer vulnerability to mid-season droughts. ICRAF has studied improved fallow systems intensively over the past 7 years. Improved fallows follow a rotation between cereal crops and tree-legume fallow. The duration of trees in the cycle depends upon the level of soil degradation and the nature of the rainfall. Coppicing fallows are newer, but follow a similar principle. These short rotation agroforestry systems are attractive to small-scale farmers because they improve soil nutrient status and water relations. They also have high potential to sequester $\mathrm{C}$ in both the aboveground and belowground biomass (Table 3). While these systems are cut frequently, the average aboveground carbon stocks exceed stocks in degraded land, cropland or pastures. Belowground $\mathrm{C}$ storage in these systems represents the potential for long-term $\mathrm{C}$ storage, as long as trees remain in the rotation, but the storage capacity is largely dependent upon soil texture and total rainfall. Nitrous oxide emissions following the leguminous tree fallows was found to be almost 10 times that of unfertilized maize (Chikowo et al. 2003) but these levels were still extremely low in comparison to the amount of $\mathrm{C}$ stored.

Restoration of degraded land using improved fallows has the potential no only to sequester significant amounts of $\mathrm{C}$ from the atmosphere, it also offers opportunities for improving rural livelihoods by turning unproductive land into productive land that can produce food, wood and other tree products, and generate income.

\section{Adaptation}

The last decade of the past millennium witnessed weather patterns and global temperatures outside of the range in the millennium as a whole, and the likelihood of climate change (with 'climate' lagging behind actual weather, by definition) that brings the global average temperature into a new realm is broadly accepted. Yet, for many places on earth, the new climate, or the trajectory of the transient climate if we recognize continuous change, will not be globally new, but already exists somewhere else. Hence, from a local perspective we may consider the issue of 'climate shift', which focuses attention on the lateral flow of organisms, farming systems and technologies that may be needed to cope with this change.

Fig. 4 Tradeoffs between carbon stocks and social profitability of land use systems in Cameroon (adapted from Gokowski et al. 2001)

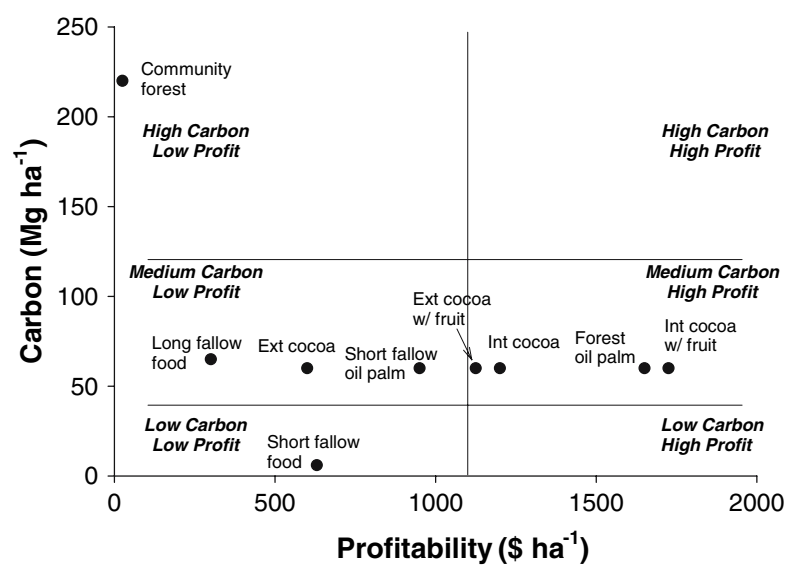


Table $3 \mathrm{C}$ stocks $\left(\mathrm{Mg} \mathrm{ha}^{-1}\right)$ in improved fallow systems (adapted from Albrecht and Kandji, 2003 and assuming that biomass is $47 \% \mathrm{C}$ )

\begin{tabular}{lcccr}
\hline Fallow species & Aboveground & Belowground & Fine root & Total \\
\hline 12-month-old fallows & & & & \\
Crotolaria grahamiana & 4.0 & 1.3 & - & 5.3 \\
Crotolaria calothyrsus & 9.9 & 3.3 & - & 13.2 \\
Cajanus cajan & 4.0 & 1.8 & - & 5.8 \\
Senna spectabilis & 3.3 & 2.3 & - & 5.5 \\
Sesbania sesban & 6.7 & 3.4 & - & 10.1 \\
Tephrosia vogelii & 5.1 & 1.9 & - & 7.0 \\
18-month-old fallows & & & & \\
Crotolaria grahamiana & 11.6 & 5.1 & 1.0 & 17.7 \\
Crotolaria paulina & 9.3 & 6.4 & 1.7 & 31.9 \\
Tephrosia candida & 14.6 & 15.6 & 1.3 & \\
22-month-old fallows & & & 1.1 & 21.3 \\
Crotolaria calothyrsus & 12.7 & 7.3 & 1.3 & 23.5 \\
Sesbania sesban & 17.3 & 5.1 & 1.1 & 25.0 \\
Grevillia robusta & 15.3 & 8.3 & & 30.5 \\
Eucalyptus saligna & 20.4 & 9.0 & & \\
\hline
\end{tabular}

Climates that are currently on the extreme of the distribution, such as tropical lowlands at the bottom of the elevational gradients as well as the latitudinal ones, may experience novel climates. The similarity of the climates on any two places on earth (or place A now and place B in future) requires a certain level of lumping of fine-level details (e.g., specific rainfall distribution). But, the main message for 'adaptation' is that answers to many of the location specific problems to be expected due to a misfit of germplasm and management systems to future climates, may be resolved by learning from experience elsewhere.

While adapting to changes in long-term averages may be feasible through technology and germplasm transfer, increased climate variability with concomitant increased frequencies of extreme events poses a greater challenge, particularly in the semi-arid tropics (SAT). In order to understand how adaptation to increased climate variability might be accomplished, it is fruitful to look at how populations are coping with current climate variability and extreme events.

Vulnerability of dryland agriculture in the SAT is distinguished by the high incidence of rainfall related production risk. The consequences range from slower diffusion of more profitable but riskier technologies, to spatially diversified but more fragmented landholdings, and even to higher population growth rates to compensate for the absence of an income safety net outside the family. This can exact a heavy toll on human welfare, as shown in the Indian SAT in the mid 1980s. Rural financial markets were fragmented, which did not allow households to save and borrow to smooth income variability, insurance markets were incomplete, and futures price markets were nonexistent or rudimentary. While the situation has improved through evolution of self-help groups and government credit schemes, vulnerability among marginalized farming population remains.

Empirical research facilitated by panel data from ICRISAT's Village Level Studies (VLS) provides a better understanding of when and under what conditions risk and the household's vulnerability play a significant role in conditioning human welfare. For the 
overwhelming majority of cultivator households in the SAT, the main source of vulnerability is conditioned by crop revenue risk. However, as extreme events become more frequent, production risk will increase due to higher yield variability, which will translate to uncertainty in crop revenue. High rainfall uncertainty also manifests itself in seasonal labor demand patterns that can change markedly from 1 year to the next. In the VLS, net crop revenue risk was the most important source of income variability for most farm households. Net crop revenue risk depends on variability from five sources: input prices, input levels, planted areas, output prices, and yields. More recent results from VLS surveys show that farm households increasingly diversify their sources of income to include livestock, non-farm income and remittances from out-migration.

Bidinger et al. (1991) studied the consequences of mid 1980s drought in India on the economic, health, and nutritional consequences of drought in Dokur, a village representative of the wetter irrigated villages where tank and well irrigation was common. Although this drought was very harsh, grain price stability and the widespread availability of consumption credit permitted villagers to maintain their consumption pattern of normal years. However, due to lack of public works programs, laborers, particularly women workers, endured unemployment. The scarcity of clean water, compounded by a severe shortage of electricity, led to a sizeable increase in water related morbid symptoms in the second drought year: diarrhea, eye infections, and scabies. Adaptation to drought followed a progression as illustrated by Jodha (1975):

- Restructuring of current farm activities to maximize effective availability of products (including a variety of salvage operations).

- Minimization of current commitments, de-emphasizing current consumption and reallocating available resources to protect the potentially productive enterprises like non-milking of animals to permit adequate milk for young calves and plowing back of practically the whole of the returns from milk production for sustaining the animal enterprise.

- Disposal of inventories of home produced goods as well as purchased goods stocked for some planned use such as marriage etc

- Sale or mortgage of assets.

- Out-migration with animals, etc.

The impact of drought, when farmers are unable to protect their production base during the drought year, is the loss of production during the drought year and the loss of productive capacity for subsequent years. For example, the loss of draft power during the drought year, results in reduced future production due to inability to cultivate the same area, delayed sowing, and adoption of less intensive methods of cultivation in the following years with adequate rains. In the case of livestock enterprises, the loss of the productive stock built over a long period (dictated partly by biological factors in the case of home-bred stock) is a permanent loss of productive capacity of the enterprise. Nonconception due to under-feeding in the drought year also has forward reaching implications for herd productivity. Thus, the effects of drought (or other extreme events) go beyond the immediate effects, and impact farmers' ability to produce and react to changing conditions and new opportunities in the future. The challenge for scientists, policy makers, and land managers working on developing productive adaptation strategies is to strengthen current farming practices and farming systems to make them less vulnerable to climate variability. 
For agro-ecosystems farmer management can play a large role in adaptation, yet agroecosystems differ in the way they sustain the farmer's agility to respond to external pressures, stresses and fluctuations. The concept of 'sustainagility' (allowing farmer's agility to continue) may capture the dynamic complements to the 'sustainability' assessment of whether or not current systems can survive. Sustainability at any level of complexity, from sustainability of cropping systems to that of livelihoods, can be based on the sustainability of its components, or on the agility in finding and fitting in new components. We can thus identify a number of sustainagility aspects (Fig. 5). Sustainable livelihood options outside of agriculture will not be considered in detail here, but will have to form the escape route for the vast majority of today's rural population, as it has already done in the 'developed' world as the result of agricultural transformation.

The resource base for sustainagility can be viewed in the light of the five types of capital recognized in recent natural resource management literature (Carney 1998): natural resource, human, social, physical and financial capital, with partial but incomplete options for exchange between capital types (Fig. 6). Adaptation of agro-ecosystems-and thus sustainagility — can be based on essentially two mechanisms, one internal and one external to the current system. Agro-ecosystems, especially those rich in agrodiversity and biological resources (Natural resource capital), can adapt (depending on their Human and Social capital) by increasing the use of currently under-exploited local resources, or on the basis of (locally or globally) new technology (new crops, new cultivars, new management practices, new external inputs), depending on their Financial, Human and Social capital. An indication of the types of capital required for the various sustainagility aspects is given in Fig. 7.

Fig. 5 Relationship between sustainability and sustainagility at different spatial scales

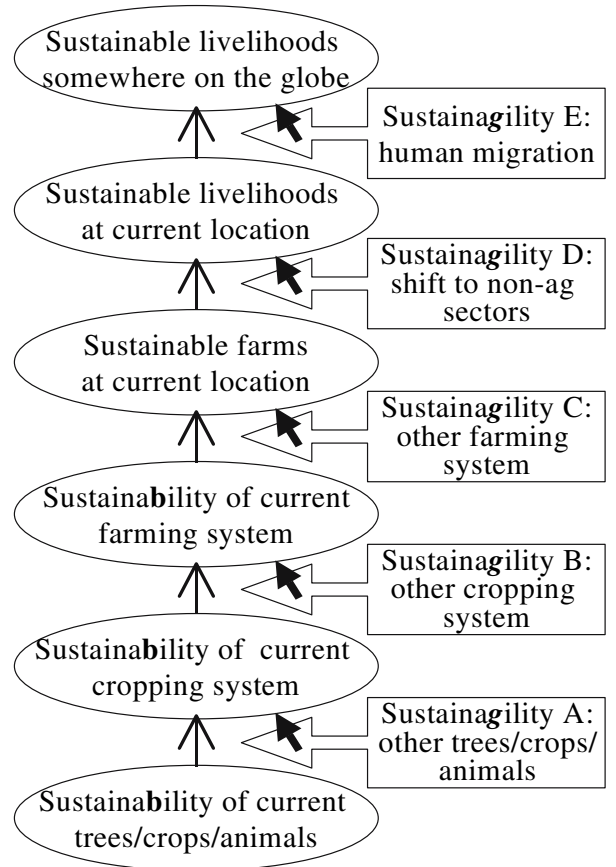


Fig. 6 Five types of capital involved in development pathways (Carney 1998)
Five types of capital:

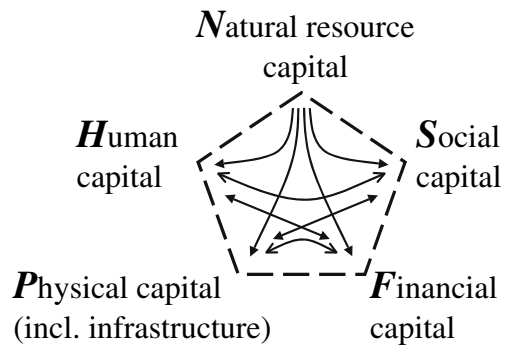

Fig. 7 Resource base for local and externally acquired new components that can be incorporated into farming systems during an adaptation process $(\mathrm{N}, \mathrm{H}, \mathrm{S}, \mathrm{P}$ and $\mathrm{F}$ refer to the five types of capital distinguished in Fig. 6 )

\section{Sustainagility in relation to agro-ecosystem complexity: Internal and external sources of adaptation and their limits}

The likelihood of externally driven adaptation is greater in the simple agro-ecosystems of the more developed parts of the world, with effective 'technology delivery systems'. Research and knowledge delivery systems are expensive, so they depend on rigorous priority setting mechanisms identifying the few components with the greatest potential market value. Agricultural research has by and large supported a drive towards the simplification of agro-ecosystems, at least in part because it is less effective in dealing with more complex systems even if these would be superior (Vandermeer et al. 1998). Access to the fruits of this increasingly commercialized research depends on financial and social capital and is less likely in the less endowed parts of the world. Farmers will have to rely more on innovation from within the system if they are going to adapt to changing climates.

Sustainagility based on resources in the current landscape becomes more likely with an increasing choice of new components and resources in more complex agro-ecosystems, although we are not yet able to quantify how much complexity is required for how much resilience (Vandermeer et al. 1998). In general, smallholder farmers have diversified 
production systems. We propose a hypothesis that there is a middle range of agro-ecosystem complexity where vulnerability is highest. Farmers in these situations have little resilience based on local resources, and are not effectively reached by technologies (Fig. 8A). More simple and well-adapted agro-ecosystems are less vulnerable to climate change as these systems tend to be run by specialized farmers with access to the resources that will facilitate adaptation. More diversified farming systems suffer less from shocks and maintain the agility of farmers to adapt to changing conditions. In the absence of data, there is considerable uncertainty over the shape of the overall response (Fig. 8B).

\section{Agroforestry as a means for adaptation}

Agroforestry options may provide a means for diversifying production systems and increasing the sustainagility of smallholder farming systems. The most worrisome component of climate change from the point of view of smallholder farmers is increased interannual variability in rainfall and temperature. Tree-based systems have some obvious advantages for maintaining production during wetter and drier years. First, their deep root systems are able to explore a larger soil volume for water and nutrients, which will help during droughts. Second, increased soil porosity, reduced runoff and increased soil cover lead to increased water infiltration and retention in the soil profile which can reduce moisture stress during low rainfall years. Third, tree-based systems have higher evapotranspiration rates than row crops or pastures and can thus maintain aerated soil conditions by pumping excess water out of the soil profile more rapidly than other production systems. Finally, tree-based production systems often produce crops of higher value than row crops. Thus, diversifying the production system to include a significant tree component may buffer against income risks associated with climatic variability.

Research into the contributions of agroforestry in buffering against climate variability is not well advanced. We have begun looking at ongoing trials and reanalyzing results to see what we can learn about the performance of different systems in exceptional years. One system that we have looked at closely is the improved fallow system that is practiced in many areas of East and Southern Africa, described above. These systems greatly improve maize yields on degraded soils where nitrogen is limiting production. A modeling exercise
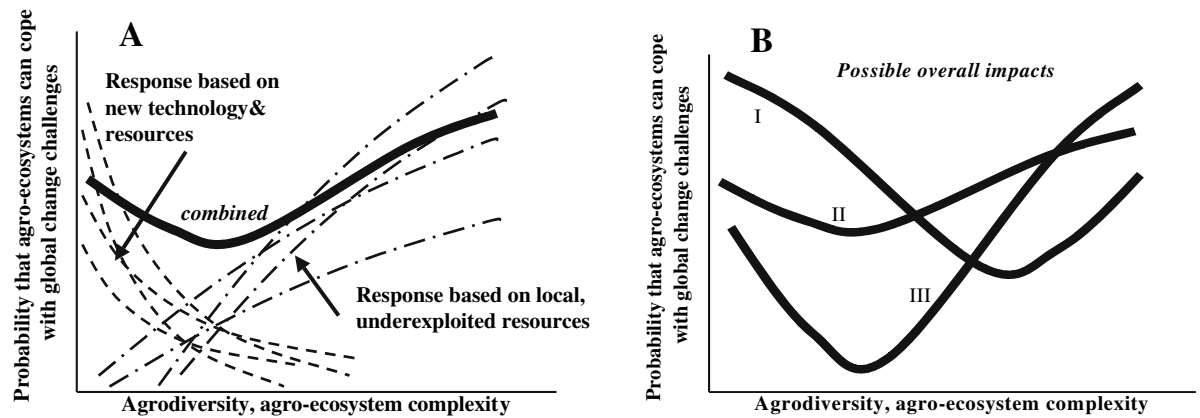

Fig. 8 Illustration of the hypothesis that the probability that agro-ecosystems will be able to cope with the challenges of global change depends on the agrodiversity and complexity of current agro-ecosystems, based on resilience and technology-based adaptation (A). It is likely that systems of intermediate complexity will be the most vulnerable, but there is large uncertainty on the shape of the curve, as shown by lines I, II and III (B) 
suggested that this system might maintain maize yields in dry years when traditional practices give very low yields (Fig. 9). This ability to maintain yields may be due to a number of factors that are improved with this system including soil physical properties, water holding capacity, biological properties, and soil nutrient status (Albrecht and Kandji 2003).

Another important agroforestry system which is well-known to buffer against production risk associated with climate variability is the parkland or scattered tree systems (Ong and Leakey 1999). In the traditional farmed parklands of West Africa, dense shading by shea butter trees (Vitellaria paradoxa) and néré (Parkia biglobosa) often reduces millet yield by $50-80 \%$ (Kater et al. 1992). Nevertheless, the trees are highly valued by farmers because economic yields from marketable tree products compensate for the loss of crop yield. In semiarid Kenya, farmers have recently developed an intensive parkland system using the fast-growing indigenous species Melia volkensii (Meliaceae), which is reputed to be highly compatible with crops and can provide high value timber in 5-10 years (Stewart and Blomley 1994).

To determine whether growing M. volkensii trees in croplands is cost effective or not, Ong et al (1999) compared the value of timber products gained with that of the crop value lost due to competition over an 11-year rotation at Kitui district, Kenya. The balance sheet does not take into account costs for seed, cultivation, tree planting stock or labor into account, which would increase the surplus of cash from the tree products because in recent years, crop failure occurs $50 \%$ of the time. Their estimates show that at the end of the rotation, the accumulated income from tree products exceeds the accumulated value of crop yield lost through competition by US\$10 or $42 \%$ during average years and US\$22 or $180 \%$ with the assumption of $50 \%$ crop failure due to drought. (In this district of Kenya, on average six of the 16 cropping seasons have failed). Factors which encourage farmers to plant M. volkensii include good financial returns in a relatively short time, strong demand for the product, high value timber and the ability to produce a range of products continuously even in drought years, when crops normally fail.

Our hypothesis is that on poor soils, the long-term prospects of systems purely based on annual food crops are bleak and a transition into tree-based farming offers better prospects. In practice, the transition to tree-based systems often depends upon temporary urban employment or remittances from overseas labor. Government support will be required to

Fig. 9 Modeled maize grain yields in improved fallow rotations in Makoka, Malawi as a function of growing season precipitation (Chirwa 2003)

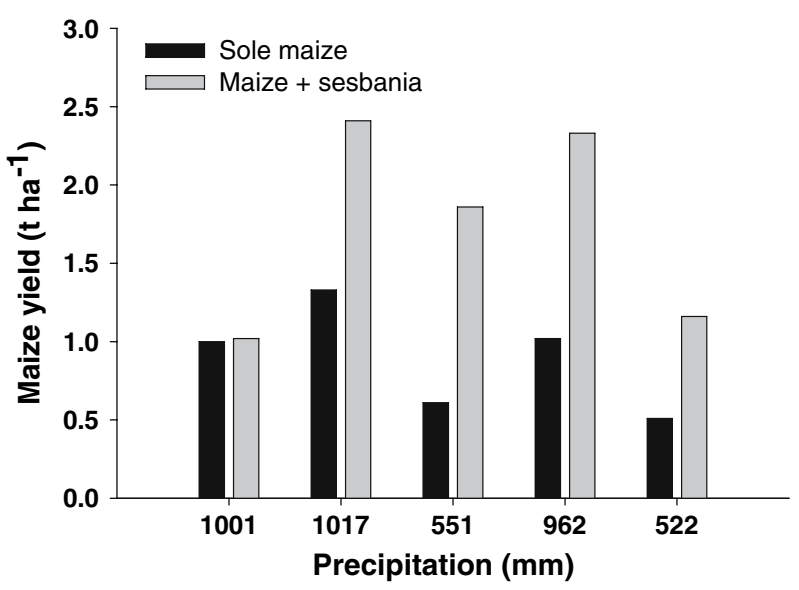


help smallholder farmers make the transition to tree-based production system, particularly when the switch entails a few years of reduced production and reduced income security.

\section{Conclusion}

Impacts of climate change will be felt on several levels in the agricultural sector: at the level of the individual crop species, the farming system (whole farm), and at the level of the natural resource base upon which rural communities depend. Preliminary vulnerability estimates may be too pessimistic for many agricultural systems with high adaptive capacity, but there clearly are limits to adaptation within agriculture, and this may put pressure on other sectors to absorb some of the impact. Impacts will be felt most by rural poor in developing countries, who are the most vulnerable because of their low adaptive capacity. The adaptive capacity of farmers in developing countries is severely restricted by heavy reliance on natural factors and lack of complementary inputs and institutional support systems.

The concepts of resilience and sustainability are well established in agriculture and can be linked directly to the discussions within the climate change arena about adaptation and mitigation. Thus, policy makers can draw upon a substantial body of knowledge on how to enhance the adaptive capacity and mitigation potential of agricultural systems. Agroforestry management systems offer important opportunities for creating synergies between actions undertaken for mitigation and activities undertaken for adaptation. Within international fora, there is much talk about 'mainstreaming' adaptation into planning processes. The concept of 'sustainagility' provides a constructive framework for national planning to reduce vulnerability of the agricultural sector to climate change.

We have shown above, through the specific case of agroforestry, that some mitigation options also provide opportunities to increase the resilience of agricultural systems. These cases, where there are synergies between mitigation and adaptation ought to be privileged in the CDM. However, if agroforestry is to be used in carbon sequestration schemes such as the CDM, better information is required in several areas. For example, we need better data on aboveground and belowground $\mathrm{C}$ stocks, and the non- $\mathrm{CO}_{2}$ emissions of different agroforestry systems. Whereas agroforestry systems are primarily production systems, there will be periodic harvesting and marketing of wood products. The debate on durable wood products is ongoing, but provisions will be needed to allow farmers to market wood products from their agroforests and accounting methods will be needed to account for the lifetime of the $\mathrm{C}$ sequestered in agroforestry products. As small-scale farmers are enrolled in carbon offset projects, we will need to develop a better understanding of the implications for $\mathrm{C}$ sequestration by agroforestry and what it means to livelihoods. Finally, the CDM has very stringent rules for participation that may be beyond the reach of small-scale farmers to understand or to provide evidence of compliance. There is a need to understand the institutional requirements to allow small-scale farmers to participate in the CDM and to put appropriate institutional frameworks in place.

In the attempt to develop adaptation strategies for the agricultural sector, scientists and policy makers must consider the complex interactions of constraints created by changing climates in light of other stress factors. Government and international support in terms of research, education, and extension will be required to help farmers in developing countries cope with the additional stresses created by climate change and increased climate variability. Agroforestry can very likely contribute to increasing the resilience of tropical 
farming systems. However, our understanding of the potential of agroforestry to contribute to adaptation to climate change is rudimentary at best. Better information is required on the role of agroforestry in buffering against floods and droughts from both the biophysical (hydraulic lift, soil fertility) and financial (diversification, income risk) points of view. If we accept that farmers ability to adapt is not based on their ability to keep on doing what they are doing, where they are doing it, but rather on their ability to continually adapt to changing biophysical and economic conditions, then we will need to determine the potential of tree-based production systems in vulnerable areas by quantifying the relationship between biodiversity and sustainagility.

Agroforestry offers the potential to develop synergies between efforts to mitigate climate change and efforts to help vulnerable populations adapt to the negative consequences of climate change. The research agenda in this area is fairly well defined. Yet, much is already known and putting these ideas into practice on the ground with small-scale farmers will allow us to learn important lessons through practical experience.

\section{References}

Abeygunawardena P, Vyas Y, Knill P, Foy T, Harrold M, Steele P, Tanner T, Hirsch D, Oosterman M, Rooimans J, Debois M, Lamin M, Liptow H, Mausolf E, Verheyen R, Agrawala S, Caspary G, Paris R, Kashyap A, Sharma R, Mathur A, Sharma M, Sperling F (2003) Poverty and climate change—reducing the vulnerability of the poor through adaptation. World Bank Press

Albrecht A, Kandji ST (2003) Carbon sequestration in tropical agroforestry systems. Agric Ecosys Envi 99:15-27

Aggarwal PK, Mall RK (2002) Climate change and rice yields in diverse agro-environments of India. II. Effect of uncertainties in scenarios and crop models on impact assessment. Clim Change 52:331-343

Aggarwal PK, Sinha SK (1993) Effect of probable increase in carbon dioxide and temperature on productivity of wheat in India. J Agric Meteorol 48:811-814

ten Berge HFM, Aggarwal PK, Kropff MJ (1997) Applications of rice modelling. Elsevier Publishers, Netherlands, p 161

Bidinger PD, Walker TS, Sarkar B, Ram Murthy A, Babu P (1991) Consequences of mid-1980s drought: Longitudinal evidence from Mahbubnagar, Economics Group Progress Report, Resource Management Program. Patancheru: ICRISAT

Carney D (1998) Implementing the sustainable rural livelihoods approach, sustainable rural livelihoodswhat contribution can we make? Department for International Development, London, UK, pp 3-23

Chikowo R, Mapfumo P, Nyamugafata P, Giller KE (2003) Mineral N dynamics, leaching and nitrous oxide losses under maize following two-year improved fallows on a sandy loam soil in Zimbabwe. Plant Soil 259:315-330

Chirwa PW (2003) Tree and crop productivity in Gliricidia/Maize/Pigeonpea cropping systems in southern Malawi, Ph.D dissertation, University of Nottingham

Cleaver KM, Schreiber GA (1994) Reversing the spiral: the population, agriculture and environment nexus in sub-Saharan Africa. World Bank, Wash., DC

Crill PM, Keller M, Weitz A, Grauel B, Veldkamp E (2000) Intensive field measurements of nitrous oxide emissions from a tropical agricultural soil. Global Biogeochem Cycles 14:85-95

Dunfield PF, Topp E, Archambault C, Knowles R (1995) Effect of nitrogen fertilizers and moisture content on $\mathrm{CH}_{4}$ and $\mathrm{N}_{2} \mathrm{O}$ fluxes in a humisol: measurements in the field and intact soil cores. Biogeochemistry 29:199-222

FAO (1999) The state of food insecurity in the world. Food and Agriculture Organization of the United Nations, Rome, Italy, p 35

Gockowski J, Nkamleu GB, Wendt J (2001) Implications of resource-use intensification for the environment and sustainable technology systems in the central african rainforest. In: Lee DR, Barrett CB (eds) Tradeoffs or synergies? Agricultural intensification, economic development and the environment, CAB International, Wallingford, UK

Hansen S, Maechlum JE, Bakken LR (1993) $\mathrm{N}_{2} \mathrm{O}$ and $\mathrm{CH}_{4}$ fluxes in soils influenced by fertilization and tractor traffic. Soil Biol Biochem 25:62-1630

Huang J, Pray C, Rozelle S (2002) Enhancing the crops to feed the poor. Nature 418:678-684 
Hutsch BW (1996) Methane oxidation in soils of two long-term fertilization experiments in Germany. Soil Biol Biochem 28:773-782

Hutsch BW, Webster CP, Powlson DS (1994) Methane oxidation in soils as affected by land use, soil pH and N fertilization. Soil Biol Biochem 26:1613-1622

Hutsch BW, Webster CP, Powlson DS (1993) Long-term effects of nitrogen fertilization on methane oxidation in soil of the Broadbalk wheat experiment. Soil Biol Biochem 25:1307-1315

IPCC (2001) Climate change 2001: impacts, adaptation and vulnerability. Report of the working group II. Cambridge University Press, UK, p 967

IPCC (2000) Land-use, land-use change and forestry. Special report of the intergovernmental panel on climate change. Cambridge University Press, UK, p 375

Jain MC, Kumar K, Wassmann R, Mitra S, Singh SD, Singh JP, Singh R, Yadav AK, Gupta S (2000) Methane emissions from irrigated rice fields in Northern India (New Delhi). Nutr Cycl Agroecosys 58:75-83

Jodha NS (1975) Famine and famine policies: some empirical evidence. Econ Poli Wkly 10:1609-1623

Jones PG, Thornton PK (2003) The potential impacts of climate change on maize production in Africa and Latin America in 2055. Glob Environ Change 13:51-59

Kater LJM, Kante S, Budelman A (1992) Karite (Vitellaria paradoxa) and nere (Parkia biglobosa) associated with crops in South Mali. Agroforest Syst 18:89-105

Keller M, Mitre ME, Stallard RF (1990) Consumption of atmospheric methane in tropical soils of central Panama: Effects of agricultural development. Global Biogeochem Cycles 4:21-28

Kropff MJ, Teng PS, Aggarwal PK, Bouman B, Bouma J, van Laar HH (1996) Applications of systems approaches at the field level, vol. 2 Kluwer Acad. Pub., Netherlands, p 465

Lal M, Nozawa T, Emori S, Harasawa H, Takahashi K, Kimoto M, Abe-Ouchi A, Nakajima T, Takemura T, Numaguti A (2001) Future climate change: implications for Indian summer monsoon and its variability. Curr Sci 81:1196-1207

Mann C (1997) Reseeding the green revolution. Science 277:1038-1043

Mosier AR, Delgado JA (1997) Methane and nitrous oxide fluxes in grasslands in western Puerto Rico. Chemosphere 35:2059-2082

Nagarajan S, Joshi LM (1978) Epidemiology of brown and yellow rusts of wheat over northern India. II. Associated meteorological conditions. Plant Dis Rep 62:186-188

Ong CK, Leakey RRB (1999) Why tree crop interactions in agroforestry appear at odds with tree-grass interactions in tropical savannahs. Agroforest Syst 45:109-129

Ong CK, Wilson J, Deans JD, Mulatya J, Raussen T, Wajja-Musukwe N (2002) Tree-crop interactions: manipulation of water use and root function. Agr Water Manage 53:171-186

Palm CA, van Noordwijk M, Woomer PL, Alegre J, Arevalo L, Castilla C, Cordeiro DG, Hairiah K, KottoSame J, Moukam A, Parton WJ, Ricse A, Rodrigues V, Sitompul SM (2004) Carbon losses and sequestration following land use change in the humid tropics. Alternatives to Slash and Burn: The Search for Alternatives. Columbia University Press (in press)

Palm CA, Alegre JC, Arevalo L, Mutuo PK, Mosier AR, Coe R (2002) Nitrous oxide and methane fluxes in six different land use systems. Global Biogeochem Cycles 16:1073, doi:10.1029/2001GB001855

Rao GD, Sinha SK (1994) Impact of climatic change on simulated wheat production in India. In: Rosenzweig C, Iglesias I (eds) Implications of climate change for international agriculture: Crop Modelling Study. EPA, USA, pp 1-10

Rosegrant MW, Paisner MS, Meijer S, Witcover J (2001) Global food projections to 2020: emerging trends and alternative futures. International Food Policy Research Institute, Wash., DC, p 206

Saseendran SA, Singh KK, Rathore LS, Singh SV, Sinha SK (2000) Effects of climate change on rice production in the tropical humid climate of Kerala, India. Clim Change 44:495-514

Smaling EMA, Nandwa SN, Janssen BH (1997) Soil fertility in Africa is at stake. In: Buresh RJ, Sanchez PA, Calhoun F (eds) Replenishing soil fertility in Africa. Soil Sci Soc Am. Special publication No. 51. Madison WI, pp 47-61

Steudler PA, Bowden RD, Mellilo JM, Aber JD (1989) Influence of nitrogen fertilization on methane uptake in temperate forest soils. Nature 341:314-316

Stewart M, Blomley T (1994), Use of Melia volkensii in a semi-arid agroforestry systems in Kenya. Commonw Forest Rev 73:128-131

Tsuruta H, Ishizuka S, Ueda S, Murdiyarso D (2000) Seasonal and spatial variations of $\mathrm{CO}_{2}, \mathrm{CH}_{4}$, and $\mathrm{N}_{2} \mathrm{O}$ fluxes from the surface soils in different forms of land-use/cover in Jambi, Sumatra. In: Murdiyarso D, Tsuruta H (eds) The impacts of land-use/cover change on greenhouse gas emissions in tropical asia. Global Change Impacts Centre for Southeast Asia and National Institute of Agro-Environmental Sciences, pp 7-30 
Vandermeer J, van Noordwijk M, Anderson J, Ong C, Perfecto I (1998) Global change and multi-species agroecosystems: concepts and issues. Agric Ecosyst Environ 67:1-22

Vasil IK (1998) Biotechnology and food security for the 21st century: a real-world perspective. Nat Biotechnol 16:399-400

Wassmann R, Lantin RS, Neue HU (2000) Methane emissions from major rice ecosystems in Asia. Nutr Cycl Agroecosys 58:1-398

Weitz AM, Linder E, Frolking S, Crill PM, Keller M (2001) $\mathrm{N}_{2} \mathrm{O}$ emissions from humid tropical agricultural soils: effects of soil moisture, texture and nitrogen availability. Soil Biol Biochem 33:1077-1093 